\title{
A finding of sex similarities rather than differences in COVID-19 outcomes
}

https://doi.org/10.1038/s41586-021-03644-7

Received: 13 November 2020

Accepted: 11 May 2021

Published online: 22 September 2021

\author{
Heather Shattuck-Heidorn ${ }^{1,2} \bowtie$, Ann Caroline Danielsen ${ }^{3}$, Annika Gompers ${ }^{4}$, \\ Joseph Dov Bruch ${ }^{3}$, Helen Zhao ${ }^{5}$, Marion Boulicault ${ }^{6}$, Jamie Marsella ${ }^{7}$ \& Sarah S. Richardson ${ }^{2,7}$
} ARISING FROM T. Takahashi et al. Nature https://doi.org/10.1038/s41586-020-2700-3 (2020)

\section{Check for updates}

The sex disparity in COVID-19 mortality varies widely and is of uncertain origin. In their recent Article, Takahashi et al. ${ }^{1}$ assess immune phenotype in a sample of patients with COVID-19 and conclude that the "immune landscape in COVID-19 patients is considerably different between the sexes", warranting different vaccine and therapeutic regimes for men and women-a claim that was disseminated widely following the publication ${ }^{2}$. Here we argue that these inferences are not supported by their findings and that the study does not demonstrate that biological sex explains COVID-19 outcomes among patients. The study overstates its findings and factors beyond innate sex are treated superficially in analysing the causes of gender or sex disparities in COVID-19 disease outcomes.

Takahashi et al. measured more than 100 immune markers in a sample of patients with COVID-19 and uninfected healthcare workers (HCW). They compared male and female patients and HCW both at baseline and longitudinally over the disease course. These comparative analyses, both within sex and between sex, across patients and $\mathrm{HCW}$, at baseline and over time, yielded more than 500 findings ${ }^{1}$. Most of the findings in the paper are presented as raw data, unadjusted for possible covariates. Among the more than 200 findings from adjusted analyses, 13 (6\%) remained statistically significant after controlling for covariates (primarily age and body mass index (BMI)). This count excludes analyses on antibodies and viral load, as well as comparisons of female HCW (F_HCW) versus male HCW (M_HCW), female patients (F_Pt) versus female HCW and male patients (M_Pt) versus male HCW.

There is considerable mismatch between the claims made in the paper and the results presented in the data tables, making it challenging to understand the basis of many of these claims. The discussion section focuses on claims related to ten immune markers, positing a variety of sex differences across diverse analyses (reconstructed in Table 1). The expanded data tables demonstrate that nine of these claims are based on raw data and do not hold true in adjusted analyses. For example, interleukin-18 (IL-18) and IL-8, emphasized in the abstract and discussion as higher in male patients, show a sex difference only in baseline-unadjusted analyses of the smaller cohort. This indicates that these reported sex differences in immunological response are better explained by factors other than biological sex.

Similarly, attempting to address the potential role of these markers in disparate outcomes between men and women, Takahashi et al. associate lower levels of activated $\mathrm{T}$ cells at baseline with poorer outcomes among men, but not among women, in a subsample of 12 patients who deteriorated during the course of the disease ( 6 male and 6 female). However, as fig. 4 demonstrates, deteriorated male patients are older ${ }^{1}$. After adjusting for age, there are no sex differences in activated T cells among the patient samples.
Although statistical significance is not the only consideration when evaluating study results, the authors use statistical significance to summarize their own results and imply that the central findings remain statistically significant after adjustment. Particularly considering the sweeping scope of the study's conclusions, combined with the study's limited sample size, large confidence intervals, few repeat measures for many participants in the longitudinal cohort, and lack of clinical discussion of effect sizes, statistical significance remains an important guidepost for contextualizing the study's findings.

Three findings that are described as sex differences ${ }^{1}$ are actually differences within sexes that do not correspond with between-sex differences (Table 1). For example, CCL5 differs at baseline between female patients who would later deteriorate ( $F_{-}$deteriorated) and those who remained stable ( $\mathrm{F}_{-}$stabilized) $\left(n=5 \mathrm{~F}\right.$ _deteriorated; $14 \mathrm{~F}_{-}$stabilized, adjusted difference: $0.39,95 \%$ confidence interval $(0.03,0.74)$, $P=0.03)$, with no such difference among male patients who deteriorated and those who remained stable ( $n=6 \mathrm{M}$ _deteriorated; $10 \mathrm{M}$ _stabilized, adjusted difference: $0.16,95 \%$ confidence interval $(-0.23,0.54)$, $P=0.70)$. However, comparing the difference-in-difference, there is no evidence that the change in CCL5 between deteriorated and stabilized patients differs between the sexes (adjusted difference: 0.23, $95 \%$ confidence interval $(-0.18,0.64), P=0.25)$. Such within-sex differences without accompanying between-sex differences cannot be interpreted as indicating sex-specific disease progression between men and women.

Overall, Takahashi et al. present three findings that are significant after adjustment and can properly be conceptualized as sex differences $^{1}$ : at baseline, numbers of non-classical monocytes (ncMono) were higher in male patients ( $n=21$ female and 16 male) and activated CD8 T cell numbers were higher in female patients ( $n=21$ female and 16 male), and male patients had higher levels of CCL5 in longitudinal analysis ( $n=48$ female and 43 male) (Table 1$)$.

There are also three findings of a greater difference-in-difference that maintain significance after adjustment: at baseline, IL-8 was higher in both male and female patients compared with $\mathrm{HCW}$, but the increase in IL-8 in male patients relative to male $\mathrm{HCW}$ was greater than the increase in female patients relative to female HCW $\left(n=19 \mathrm{~F}_{-} \mathrm{Pt}, 28 \mathrm{~F}_{-} \mathrm{HCW}, 16 \mathrm{M} \mathrm{Pt}\right.$ and $15 \mathrm{M}$ _HCW); at baseline, CXCL-10 was higher in both male and female patients compared to $\mathrm{HCW}$, but the increase in male patients relative to male $\mathrm{HCW}$ was greater than the increase in female patients relative to female HCW ( $n=19 \mathrm{~F}_{-} \mathrm{Pt}, 28 \mathrm{~F}_{-} \mathrm{HCW}, 16 \mathrm{M}$ _Pt and $\left.15 \mathrm{M} \_\mathrm{HCW}\right)$; and, in longitudinal analyses, CCL5 increased in male patients compared with male HCW, but did not differ between female patients and female HCW ( $n=48$ F_Pt, 28 F_HCW, 43 M_Pt and $15 \mathrm{M}_{-}$HCW) (Table 1).

'Women and Gender Studies Program, University of Southern Maine, Portland, ME, USA. ${ }^{2}$ Studies of Women, Gender and Sexuality, Harvard University, Cambridge, MA, USA. ${ }^{3}$ Social and Behavioral Sciences, Harvard T.H. Chan School of Public Health, Boston, MA, USA. ${ }^{4}$ Department of Obstetrics and Gynecology, Beth Israel Deaconess Medical Center, Boston, MA, USA.

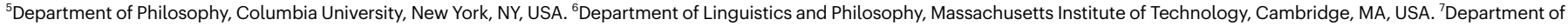
the History of Science, Cambridge, MA, USA. ${ }^{凶}$ e-mail: heather.shattuckheidorn@maine.edu 
Table 1 | Sex difference claims in Takahashi et al.

\begin{tabular}{|c|c|c|c|c|c|c|c|c|c|c|c|}
\hline \multirow[b]{2}{*}{$\begin{array}{l}\text { Immune } \\
\text { marker }\end{array}$} & \multicolumn{4}{|c|}{ Baseline analyses } & \multicolumn{4}{|c|}{ Longitudinal analyses } & \multicolumn{3}{|c|}{$\begin{array}{l}\text { Deteriorated versus stabilized patient } \\
\text { analyses }\end{array}$} \\
\hline & $\begin{array}{l}\text { M_ } \\
\text { Pt:F_ } \\
\text { Pt, adj. } \\
\text { for age } \\
\text { and } \\
\text { BMI }^{c}\end{array}$ & $\begin{array}{l}\text { M_Pt:M_- } \\
\text { HCW, adj. } \\
\text { for age } \\
\text { and } B M^{c}\end{array}$ & $\begin{array}{l}\text { F_Pt:F_- } \\
\text { HCW, adj. } \\
\text { for age } \\
\text { and } \mathrm{BMI}^{\mathrm{c}}\end{array}$ & $\begin{array}{l}\text { Difference } \\
\text { in } \\
\text { differences } \\
\text { between } \\
\text { M_Pt:M_ } \\
\text { HCW and F_- } \\
\text { Pt:F_HCW, } \\
\text { adj.for age } \\
\text { and BMIc }\end{array}$ & $\begin{array}{l}\text { M_Pt:F_Pt, } \\
\text { adj.for } \\
\text { age, BMI } \\
\text { and four } \\
\text { additional } \\
\text { variables }^{d}\end{array}$ & $\begin{array}{l}\text { M_Pt:M_. } \\
\text { HCW, adj. } \\
\text { for age } \\
\text { and } B M I^{e}\end{array}$ & $\begin{array}{l}\text { F_Pt:F_ } \\
\text { HCW, adj. } \\
\text { for age } \\
\text { and } \mathrm{BMI}^{\mathrm{e}}\end{array}$ & $\begin{array}{l}\text { Difference } \\
\text { in } \\
\text { differences } \\
\text { between M_ } \\
\text { Pt:M_HCW } \\
\text { and F_Pt:F_ } \\
\text { HCW, adj. } \\
\text { for age } \\
\text { and BMIc }\end{array}$ & $\begin{array}{l}\text { M_ } \\
\text { Deteriorated: } \\
\text { M_Stabilized, } \\
\text { adj. for age } \\
\text { and DFSO }\end{array}$ & $\begin{array}{l}\text { F_ } \\
\text { Deteriorated: } \\
\text { F_Stabilized, } \\
\text { adj. for } \\
\text { age and } \\
\text { DFSO }^{f}\end{array}$ & $\begin{array}{l}\text { Difference in } \\
\text { difference } \\
\text { between } M_{-} \\
\text {Deteriorated: } \\
\text { M_Stabilized } \\
\text { and F- } \\
\text { Deteriorated: } \\
\text { F_Stabilized, } \\
\text { adj.for age } \\
\text { and DFSO }\end{array}$ \\
\hline IL-8 & NS & $\begin{array}{l}\text { Higher in } \\
\text { patients }^{b}\end{array}$ & $\begin{array}{l}\text { Higher in } \\
\text { patients }^{b}\end{array}$ & $\begin{array}{l}\text { Greater diff } \\
\text { in } \mathrm{M}^{\mathrm{a}}\end{array}$ & $\mathrm{NS}^{\mathrm{b}}$ & $\begin{array}{l}\text { Higher in } \\
\text { patients }^{\text {b }}\end{array}$ & $\begin{array}{l}\text { Higher in } \\
\text { patients }^{b}\end{array}$ & $N S^{b}$ & $N S^{b}$ & $N S^{b}$ & $\mathrm{NS}^{\mathrm{b}}$ \\
\hline IL-18 & NS & $N S^{b}$ & $N S^{b}$ & $N S^{b}$ & $N S^{b}$ & $N S^{b}$ & $\begin{array}{l}\text { Higher in } \\
\text { patients }^{b}\end{array}$ & $N S^{b}$ & $N S^{b}$ & $N S^{b}$ & $N S^{b}$ \\
\hline CCL5 & $N S^{b}$ & $\begin{array}{l}\text { Higher in } \\
\text { patients }^{\text {b }}\end{array}$ & $\begin{array}{l}\text { Higher in } \\
\text { patients }^{b}\end{array}$ & $N S^{b}$ & $\begin{array}{l}\text { Higher in } \\
\mathrm{M}^{\mathrm{a}}\end{array}$ & $\begin{array}{l}\text { Higher in } \\
\text { patients }{ }^{b}\end{array}$ & $N S^{b}$ & $\begin{array}{l}\text { Greater diff } \\
\text { in } \mathrm{M}^{\mathrm{a}}\end{array}$ & $N S^{b}$ & $\begin{array}{l}\text { Higher in } \\
\text { deteriorated }\end{array}$ & $N S^{b}$ \\
\hline CXCL10 & $N S^{b}$ & $\begin{array}{l}\text { Higher in } \\
\text { patients }^{b}\end{array}$ & $\begin{array}{l}\text { Higher in } \\
\text { patients }^{b}\end{array}$ & $\begin{array}{l}\text { Greater diff } \\
\text { in } \mathrm{M}^{\mathrm{a}}\end{array}$ & $N S^{b}$ & $\begin{array}{l}\text { Higher in } \\
\text { patients }^{b}\end{array}$ & $\begin{array}{l}\text { Higher in } \\
\text { patients }^{b}\end{array}$ & $N S^{b}$ & $N S^{b}$ & NS & $N S^{b}$ \\
\hline TNSF10 & $N S^{b}$ & $N S^{b}$ & $N S^{b}$ & $N S^{b}$ & $N S^{b}$ & $N S^{b}$ & $N S^{b}$ & $\mathrm{NS}^{\mathrm{b}}$ & $\mathrm{NS}^{\mathrm{b}}$ & NS & $N S^{b}$ \\
\hline MCSF & $N S^{b}$ & $\begin{array}{l}\text { Higher in } \\
\text { patients }^{b}\end{array}$ & $N S^{b}$ & $N S^{b}$ & $\mathrm{NS}^{\mathrm{b}}$ & $\begin{array}{l}\text { Higher in } \\
\text { patients }^{b}\end{array}$ & $\begin{array}{l}\text { Higher in } \\
\text { patients }^{b}\end{array}$ & $N S^{b}$ & $\mathrm{NS}^{\mathrm{b}}$ & NS & $N S^{b}$ \\
\hline IL-15 & $\begin{array}{l}\text { Not } \\
\text { shown }\end{array}$ & $\begin{array}{l}\text { Not } \\
\text { shown }\end{array}$ & $\begin{array}{l}\text { Not } \\
\text { shown }\end{array}$ & Not shown ${ }^{b}$ & $\begin{array}{l}\text { Not } \\
\text { shown }\end{array}$ & $\begin{array}{l}\text { Not } \\
\text { shown }\end{array}$ & $\begin{array}{l}\text { Not } \\
\text { shown }\end{array}$ & Not shown ${ }^{b}$ & $\mathrm{NS}^{\mathrm{b}}$ & NS & $\mathrm{NS}^{\mathrm{b}}$ \\
\hline ncMono & $\begin{array}{l}\text { Higher } \\
\text { in } \mathrm{M}^{\mathrm{a}}\end{array}$ & $N S^{b}$ & $N S^{b}$ & $\mathrm{NS}^{\mathrm{b}}$ & $N S^{b}$ & $\mathrm{NS}^{\mathrm{b}}$ & $N S^{b}$ & $N S^{b}$ & $\mathrm{NS}^{\mathrm{b}}$ & $N S^{b}$ & $\mathrm{NS}^{\mathrm{b}}$ \\
\hline $\begin{array}{l}\text { T cell } \\
\text { activity: } \\
\text { CD38 } \\
\text { and } \\
\text { HLA-DR } \\
\text { T cells } \\
\text { (CD4) }\end{array}$ & NS & $N S^{b}$ & $\begin{array}{l}\text { Higher in } \\
\text { patients }\end{array}$ & $\mathrm{NS}^{\mathrm{b}}$ & $N S^{b}$ & $\begin{array}{l}\text { Higher in } \\
\text { patients }^{\text {b }}\end{array}$ & $\begin{array}{l}\text { Higher in } \\
\text { patients }^{\text {b }}\end{array}$ & $N S^{b}$ & NS & $\mathrm{NS}^{\mathrm{b}}$ & $N S^{b}$ \\
\hline $\begin{array}{l}\text { T cell } \\
\text { activity: } \\
\text { CD38 } \\
\text { and } \\
\text { HLA-DR } \\
\text { T cells } \\
\text { (CD8) }\end{array}$ & $\begin{array}{l}\text { Higher } \\
\text { in } \mathrm{F}^{\mathrm{a}}\end{array}$ & $N S^{b}$ & $\begin{array}{l}\text { Higher in } \\
\text { patients }\end{array}$ & $N S^{b}$ & $\mathrm{NS}^{\mathrm{b}}$ & $\begin{array}{l}\text { Higher in } \\
\text { patients }^{\text {b }}\end{array}$ & $\begin{array}{l}\text { Higher in } \\
\text { patients }^{\text {b }}\end{array}$ & $\mathrm{NS}^{\mathrm{b}}$ & NS & $N S^{b}$ & $N S^{b}$ \\
\hline \multicolumn{12}{|c|}{$\begin{array}{l}\text { Summary of findings for the ten immune markers that underlie claims of important differences between males (M) and females }(\mathrm{F}) \text { in the discussion and abstract of Takahashi et al..' 'Not showr } \\
\text { indicates data not shown or the effect was not tested for. Bold indicates findings that, in adjusted analyses, contradict claims of sex difference made in the discussion or abstract ( } n=9 \text { ). Italics } \\
\text { indicates findings described as sex differences that are better characterized as within-sex differences without corresponding between-sex differences ( } n=3 \text { ). DFSO, days from symptom offse } \\
\text { MCSF, macrophage colony-stimulating factor; NS, not significant. }\end{array}$} \\
\hline
\end{tabular}

However, none of these findings of sex differences appear robust across the conducted analyses. For instance, while baseline levels of ncMono and CD8 T cells differ in the direct comparison between female and male patients, the sex difference disappears in the corresponding difference-in-differences analysis. In addition, none of the markers that do show sex differences in cohorts $A$ and $B$ emerge as predictive variables of interest in analyses comparing stable with deteriorated patients. Whilewe fully recognize that immune differences would not necessarily beexpected to be consistent across analyses, the lack of consistency, illustrated in Table 1, is part of a triangulating web of observations suggesting that the sex difference findings do not show a strong signal and may be artefactual.

Biological sex differences are the only causal model considered in the study. While it is plausible that sex-related biological variables may have a role in explaining sex disparities in COVID-19, strong evidence not cited by the researchers suggests a large role for social and other variables in producing the sex differences they seek to explain. For example, research demonstrates substantial variation in the magnitude and direction of the COVID-19 sex disparity across geographical localities, amongst racial and ethnic groups, and over time; these patterns are better explained by contextual factors than biological sex differences ${ }^{3-6}$. Previous research also predicts that occupational sex segregation ${ }^{7}$ and comorbidities are likely to largely explain COVID-19 sex disparities, as observed in recent SARS-CoV-1 and Middle East respiratory syndrome (MERS) epidem$\mathrm{ics}^{8-10}$. Other studies document gender differences in conformity to COVID-19 public health guidelines ${ }^{11}$. Further research raises questions about whether aggregate patterns of higher COVID-19 mortality in men constitute a COVID-19-specific sex disparity, given men's pre-existing higher aggregate mortality rates before the pandemic ${ }^{12}$.

Gender influences both exposure to the virus and susceptibility to severe outcomes. Occupational worksegregation or adherence tobehaviourssuch as mask wearing mediate viral load and therefore disease severity ${ }^{13}$.Chronic diseases, which are differentially distributed across men and women due 
to both gender-and sex-related factors, are also important contributors to COVID-19 progression and outcomes ${ }^{14}$. Notably, immune function is modified during the progression of many chronic diseases ${ }^{15}$. This is one avenue by which observed differences in immune markers may reflect gendered chronic conditions and associated immune responses rather than sex-specific biological mechanisms in response to the SARS-CoV-2 virus.

In these ways, the claims ${ }^{1}$ that sex differences in immune factors underlie COVID-19 sex disparities and merit "sex-dependent approaches to prognosis, prevention, care, and therapy for patients with COVID-19" are not only unsupported by the data, they are also not appropriately contextualized within the empirical literature on the primary role of social factors as causes of sex disparities in respiratory infectious disease epidemics.

The study by Takahashi et al. ${ }^{1}$ should be characterized as an exploratory study of possible associations between immunological variables and sex disparities in COVID-19 outcomes. The study presents largely null findings that support an assessment of male-female similarities in immune response to the SARS-CoV-2 virus. We stress that in no way does this study provide a foundation for clinical practice or for public health strategies to ameliorate COVID-19 sex disparities.

\section{Online content}

Any methods, additional references, Nature Research reporting summaries, source data, extended data, supplementary information, acknowledgements, peer review information; details of author contributions and competing interests; and statements of data and code availability are available at https://doi.org/10.1038/s41586-021-03644-7.

1. Takahashi, T. et al. Sex differences in immune responses that underlie COVID-19 disease outcomes. Nature 588, 315-320 (2020)

2. Mandavilli, A. Why does the coronavirus hit men harder? A new clue. The New York Times https://www.nytimes.com/2020/08/26/health/coronavirus-men-immune.html (26 August 2020).
3. US gender/sex COVID-19 data tracker. Gender Sci Lab https://www.genderscilab.org/ gender-and-sex-in-covid19 (2020)

4. Islam, N., Khunti, K., Dambha-Miller, H., Kawachi, I. \& Marmot, M. COVID-19 mortality: a complex interplay of sex, gender and ethnicity. Eur. J. Public Health 30, 847-848 (2020).

5. Dehingia, N. \& Raj, A. Sex differences in COVID-19 case fatality: do we know enough? Lancet 9, e14-e15 (2021).

6. Rushovich, T. et al. Sex disparities in COVID-19 mortality vary across US racial groups. J. Gen. Intern. Med. 36, 1696-1701 (2021).

7. Adams, R. B. Gender equality in work and COVID-19 deaths. Covid Economics (11 May 2020).

8. Chan-Yeung, M. \& Xu, R. H. SARS: epidemiology. Respirology 8 (Suppl), S9-S14 (2003).

9. Jia, N. et al. Case fatality of SARS in mainland China and associated risk factors. Trop. Med. Int. Health 14 (Suppl 1), 21-27 (2009).

10. Yang, Y.-M. et al. Impact of comorbidity on fatality rate of patients with Middle East respiratory syndrome. Sci. Rep. 7, 11307-11309 (2017).

11. Galasso, V., et al. Gender Difference in COVID-19 Related Attitudes and Behavior: Evidence from a Panel Survey in Eight OECD Countries; https://www.nber.org/papers/w27359 (National Bureau of Economic Research, 2020).

12. Krieger, N., Chen, J. T. \& Waterman, P. D. Excess mortality in men and women in Massachusetts during the COVID-19 pandemic. Lancet 395, 1829 (2020).

13. Gandhi, M., Beyrer, C. \& Goosby, E. Masks do more than protect others during COVID-19. reducing the inoculum of SARS-CoV-2 to protect the wearer. J. Gen. Intern. Med. 35, 3063-3066 (2020).

14. Zhang, J. et al. Risk factors for disease severity, unimprovement, and mortality in COVID-19 patients in Wuhan, China. Clin. Microbiol. Infect. 26, 767-772 (2020).

15. Hotamisligil, G. S. Inflammation and metabolic disorders. Nature 444, 860-867 (2006)

Author contributions All authors contributed to conceptualization and design. H.S.H. A.G A.C.D., J.D.B. and S.S.R. performed the analysis. H.S.H. and S.R. drafted the manuscript, and all authors contributed to revisions and editing.

Competing interests The authors declare no competing interests.

Additional information

Correspondence and requests for materials should be addressed to Heather Shattuck-Heidorn.

Reprints and permissions information is available at http://www.nature.com/reprints. Publisher's note Springer Nature remains neutral with regard to jurisdictional claims in published maps and institutional affiliations.

(c) The Author(s), under exclusive licence to Springer Nature Limited 2021 


\section{Reply to: A finding of sex similarities rather than differences in COVID-19 outcomes}

https://doi.org/10.1038/s41586-021-03645-6

Published online: 22 September 2021

Check for updates

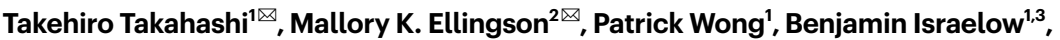 \\ Carolina Lucas', Jon Klein', Julio Silva', Tianyang Mao', Ji Eun Oh', Maria Tokuyama', \\ Peiwen Lu', Arvind Venkataraman', Annsea Park', Feimei Liu ${ }^{1,4}$, Amit Meir ${ }^{5}$, Jonathan Sun ${ }^{6}$, \\ Eric Y. Wang' ${ }^{1}$, Arnau Casanovas-Massanaa ${ }^{2}$, Anne L. Wyllie ${ }^{2}$, Chantal B. F. Vogels' ${ }^{2}$, \\ Rebecca Earnest ${ }^{2}$, Sarah Lapidus ${ }^{2}$, Isabel M. Ott ${ }^{2,7}$, Adam J. Moore ${ }^{2}$, Albert Shaw ${ }^{3}$, \\ John B. Fournier ${ }^{3}$, Camila D. Odio ${ }^{3}$, Shelli Farhadian ${ }^{3}$, Charles Dela Cruz $^{8}$, \\ Nathan D. Grubaugh ${ }^{2}$, Wade L. Schulz ${ }^{9,10}$, Aaron M. Ring' ${ }^{1}$, Albert I. Ko ${ }^{2}$, Saad B. Omer ${ }^{2,3,11,12 \bowtie}$ \& \\ Akiko Iwasaki ${ }^{1,13} \bowtie$
}

REPLYING TO H. Shattuck-Heidorn et al. Nature https://doi.org/10.1038/s41586-021-03644 (2021)
In the accompanying Comment, Shattuck-Heidorn et al. ${ }^{1}$ argue that in our study ${ }^{2}$ the inferences are not supported by the data and the study is not appropriately contextualized within the empirical literature on the primary role of social factors in infectious disease epidemics. Our study should be read in the context of the large body of studies on the biological sex differences of immune responses. Many studies have shown that human immune responses against infections differ between the sexes ${ }^{3}$, and this is also the case in COVID-19 ${ }^{4,5}$. Such evidence in human studies is supported by a large body of animal studies that are devoid of any confounding social, behavioural and demographic factors, demonstrating that there are sex differences in immune responses across species, from fruitflies to mice ${ }^{3}$. In a mouse model of SARS-CoV, female mice are protected owing to the influence of female sex hormones on the immune system ${ }^{6}$. A recent study using a mouse model of SARS-CoV-2 infection also demonstrated a significant survival advantage in female mice $^{7}$; male mice produce larger inflammatory responses with significantly higher expression of gene signatures of crucial cytokines and chemokines compared with female mice ${ }^{7}$, which is in line with our findings ${ }^{2}$. The role of sex and gender in the causal pathway is complex along the time course of infection (exposure, symptomatic illness, moderate and severe disease), and it involves biological and contextual factors. However, the purpose of our study was to examine the role of biological sex in immune responses among hospitalized patients, for which there is evidence of significant gender-based differences ${ }^{8}$.

Nevertheless, we are mindful of the limitations of our study, such as the small sample sizes, and of its exploratory nature; however, we disagree with the conclusion ${ }^{1}$ that our study "presents largely null findings that support an assessment of male-female similarities in immune response to the SARS-CoV-2 virus".

Shattuck-Heidorn et al. constructed table $1^{1}$ from our extended data tables $3-6^{2}$ by classifying the data according to whether it was significant (that is, $P<0.05$ ). They argue that some of the data that are significant in the baseline analysis are no longer significant after adjusting for age and body mass index (BMI), and that the factors in which there were statistically significant differences in the baseline analysis and the longitudinal analysis are not the same, suggesting a lack of consistency. Furthermore, the authors argue that differences reported in our study are largely null and maybe even artefactual.

Our study was an exploratory, and not a hypothesis-driven analysis, with a small sample size to provide a basis for further investigations. Therefore, although we used significance testing in our own interpretations, it is wrong to interpret any results that are not statistically significant results as disproving a hypothesi ${ }^{1-}$ that is, to suggest that a lack of statistical significance indicates that there is no effect. $P$ values are a useful tool but, as has been thoroughly discussed in the biostatistical literature ${ }^{9}$, it is inappropriate to interpret them in isolation from effect sizes, sample size and study design. Arguments based solely on $P$ values lead to the dismissal of important differences. For example, by evaluating the magnitude and direction of the unadjusted and adjusted differences, as well as the statistical significance, in IL- 8 and IL-18 levels between male and female patients in cohort $A$, we identified an important difference, which has been confirmed by others as discussed below. In addition, Shattuck-Heidorn et al. ${ }^{1}$ argue that significant differences in numbers of activated CD8 T cells between stable and deteriorated males disappears after adjusting for age and BMI. This is exactly what is expected-we clearly showed that deteriorated males were older, and exhibited lower $\mathrm{T}$ cell activation, and that these factors were strongly correlated only in males.

The claim that the factors in which statistical significance is detected in the baseline and longitudinal analyses should be 'consistent ${ }^{\prime}{ }^{1}$ is based on an assumption that the same immune factors should be found in different phases of COVID-19 infection. Baseline analysis of cohort A included only the first time point, only for patients with moderate disease. The longitudinal analysis of cohort B included samples from later disease phases, with varying severity, and takes into account the overall immunological changes throughout the course of the disease.

'Department of Immunobiology, Yale University School of Medicine, New Haven, CT, USA. ²Department of Epidemiology of Microbial Diseases, Yale School of Public Health, New Haven, CT, USA. ${ }^{3}$ Department of Medicine, Section of Infectious Diseases, Yale University School of Medicine, New Haven, CT, USA. ${ }^{4}$ Department of Biomedical Engineering, Yale School of Engineering and Applied Science, New Haven, CT, USA. ${ }^{5}$ Boyer Center for Molecular Medicine, Department of Microbial Pathogenesis, Yale University, New Haven, CT, USA. ${ }^{6}$ Department of Comparative

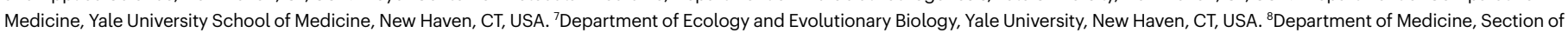

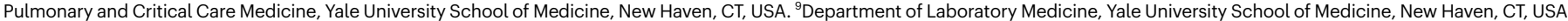

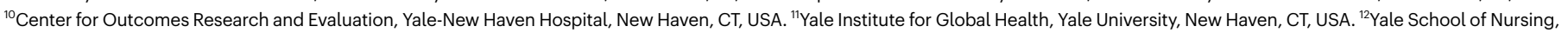

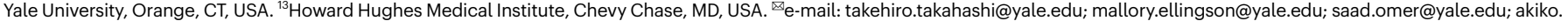
iwasaki@yale.edu 
The immune response is a dynamic process involving innate and adaptive immunity ${ }^{10}$, and cytokine levels may change by orders of magnitude over time ${ }^{11}$. Thus, these analyses are fundamentally asking different questions and would not be expected to identify the same factors.

We are confused by the authors' claim that the differences in immune phenotypes are largely null on the basis of biological sex, while at the same time they state that "observed differences in immune markers may reflect gendered chronic conditions". The biological sex differences are closely intertwined with differences due to social and demographic gender disparities, and they are not mutually exclusive. We agree that analyses of the impact of gender disparities on immune responses are very important. However, this was not the focus of our study. We explicitly focused on the biological sex differences in the COVID-19 immune responses among a defined set of patients, and did not make general claims about the biological bases of gender disparities.

In less than half a year since the publication of our study, a large body of literature is emerging to support our findings. A single-cell transcriptomic study of peripheral blood mononuclear cells from patients with COVID-19 has revealed a significantly higher abundance of non-classical monocytes (ncMono) in male patients compared with female patients ${ }^{12}$, as we reported in our baseline analysis ${ }^{2}$, which is being dismissed by Shattuck-Heidorn et al. in their table $1^{1}$. The ncMono abundance in male patients was twofold to fourfold higher compared with female patients ${ }^{12}$-the same magnitude of difference as in our study ${ }^{2}$. In addition, IL18 expression in monocytes from male patients was significantly higher than in those from female patients ${ }^{12}$. Nasal squamous epithelial cells from male patients with COVID-19 also expressed higher levels of IL18 than those from female patients ${ }^{12}$. Male patients showed higher expression in monocytes of $M Y D 88$ and $N F K B 1^{12}$, genes that encode direct regulators of pro-inflammatory cytokines including IL-8. The neutrophil:lymphocyte ratio was found to be higher in male patients ${ }^{13}$, and neutrophil activation was associated with IL-8 levels in patients with COVID-19 ${ }^{14}$. Another study used single-cell RNA-sequencing analysis to demonstrate prominent sex differences in CD8 T cells and especially in the subpopulation of $C D 161^{\text {hi }}$ mucosal-associated invariant $\mathrm{T}$ cells (MAIT cells) ${ }^{15}$. MAIT cells in males exhibited pro-apoptotic gene signatures, whereas the same cell type in females had a different set of activated gene signatures, and bioinformatic analysis of gene-expression patterns indicated that these cells interact with monocytes through CCL5-CCR1 and IL18-IL-18R ligand-receptor interactions ${ }^{15}$; IL-18 and CCL5 are the same factors for which we reported sex differences in our baseline and longitudinal analyses, respectively ${ }^{2}$. The striking concordance between our findings and others on sex differences that implicate the same parameters and associated immune pathways makes it highly unlikely that our findings are artefactual. Independent studies including ours, using different modalities and methods, support sex differences in the same immune factors and pathways.

Finally, referring to our study ${ }^{2}$, Shattuck-Heidorn et al. state ${ }^{1}$ that "We stress that in no way does this study provide a foundation for clinical practice or for public health strategies to ameliorate COVID-19 sex disparities". We simply stated that our analyses "provide a potential basis for taking sex-dependent approaches to prognosis, prevention, care, and therapy for patient with COVID-19". Science is an iterative process. Although our study in isolation may only contribute a piece of the puzzle, given the large body of studies that demonstrate sex differences during the course of COVID-19 disease and the immune response as outlined above, it is perhaps time to take these collective insights into account for future guidance in developing clinical practice and public health strategies to improve treatment and prevention for COVID-19.

In conclusion, accumulating evidence supports an important role for biological sex in immune responses against COVID-19. The heterogeneity in the disease phenotype in COVID-19 is related to the intersectional nature of a variety of factors-social, gender, race, ethnicity, disability and economic, as well as geography, age and comorbidities ${ }^{16}$. We believe that biological sex should be included as a key variable for studying infectious diseases. We hope that more studies in this area will contribute to the better understanding of disease mechanisms, as well as to the development of better treatments against acute and long COVID-19.

\section{Online content}

Any methods, additional references, Nature Research reporting summaries, source data, extended data, supplementary information, acknowledgements, peer review information; details of author contributions and competing interests; and statements of data and code availability are available at https://doi.org/10.1038/s41586-021-03645-6.

1. Shattuck-Heidorn, $\mathrm{H}$. et al. A finding of sex similarities rather than differences in COVID-19 outcomes. Nature https://doi.org/10.1038/s41586-021-03644-7 (2021).

2. Takahashi, T. et al. Sex differences in immune responses that underlie COVID-19 disease outcomes. Nature 588, 315-320 (2020).

3. Klein, S. L. \& Flanagan, K. L. Sex differences in immune responses. Nat. Rev. Immunol. 16, 626-638 (2016).

4. Bunders, M. J. \& Altfeld, M. Implications of sex differences in immunity for SARS-CoV-2 pathogenesis and design of therapeutic interventions. Immunity 53, 487-495 (2020).

5. Klein, S. L. et al. Biological sex impacts COVID-19 outcomes. PLoS Pathog. 16, e1008570 (2020).

6. Channappanavar, R. et al. Sex-based differences in susceptibility to severe acute respiratory syndrome coronavirus infection. J. Immunol. 198, 4046-4053 (2017).

7. Golden, J. W. et al. Human angiotensin-converting enzyme 2 transgenic mice infected with SARS-CoV-2 develop severe and fatal respiratory disease. JCI Insight 5, e142032 (2020).

8. Gebhard C et al. Impact of sex and gender on COVID-19 outcomes in Europe. Biol. Sex Differ. 11, 29 (2020).

9. Wasserstein, R. et al. The ASA Statement on P-values: context, process, and purpose. Am. Stat. 70, 129-133 (2016).

10. Iwasaki, A. \& Medzhitov, R. Control of adaptive immunity by the innate immune system. Nat. Immunol. 16, 343-353 (2015).

11. Lucas, C. et al. Longitudinal analyses reveal immunological misfiring in severe COVID-19. Nature 584, 463-469 (2020).

12. How, Y. et al. Multimodal single-cell omics analysis of COVID-19 sex differences in human immune systems. Preprint at https://doi.org/10.1101/2020.12.01.407007 (2020).

13. Meng Y. et al. Sex-specific clinical characteristics and prognosis of coronavirus disease-19 infection in Wuhan, China: a retrospective study of 168 severe patients. PLoS Pathog. 16 e1008520 (2020).

14. Meizlish, M. L. et al. A neutrophil activation signature predicts critical illness and mortality in COVID-19. Blood Adv. 5, 1164-1177 (2021).

15. Yu, C. et al. Mucosal-associated invariant T cell responses differ by sex in COVID-19. Med 2, 755-772.e5 (2021)

16. Shapiro, J. R., Klein, S. L. \& Morgan, R. COVID-19: use intersectional analyses to close gaps in outcomes and vaccination. Nature 591, 202 (2021).

Author contributions T.T., M.K.E., S.B,O., and A.I. drafted the manuscript. All authors helped to edit the manuscript. The Yale IMPACT Research Team authors included in the original Article contributed to sample collection, processing, raw data acquisition, and the creation and design of Yale COVID-19 study cohort, but not to the analysis of the data, so these authors have not been included in this Reply.

Competing interests The authors declare no competing interests.

\section{Additional information}

Correspondence and requests for materials should be addressed to Takehiro Takahashi, Mallory K. Ellingson, Saad B. Omer or Akiko Iwasaki.

Reprints and permissions information is available at http://www.nature.com/reprints.

Publisher's note Springer Nature remains neutral with regard to jurisdictional claims in published maps and institutional affiliations.

(c) The Author(s), under exclusive licence to Springer Nature Limited 2021 